\title{
COMPUTER VISION and SHAPE RECOGNITION
}


Volume 1: Computer-aided Specification Techniques

by J Demetrovics, $E$ Dnuth \& P Rado

Volume 2: Proceedings of the 2nd RIKEN International Symposium on Symbolic and Alegbraic Computation by Computers edited by $N$ Inada \& $T$ Soma

Volume 3: Computational Studies of the Most Frequent Chinese Words and Sounds by Ching Y Suen

Volume 4: Understanding and Learning Statistics by Computer by $M C K$ Yang \& $D H$ Robinson

Volume 6: DC Flux Parametron

A New Approach to Josephson Junction Logic by $E$ Goto \& $K F$ Loe

Volume 8: Information, Randomness \& Incompleteness Papers on Algorithmic Information Theory by $G J$ Chaitin

Volume 9: P-Prolog-A Parallel Logic Programming Language by Rong Yang

Volume 10: Intelligent Chinese Language Pattern and Speech Processing edited by P S.P Wang

Volume 12: An Introduction to Chinese, Japanese, and Korean Computing by $J K T$ Huang \& $T D$ Huang

Volume 14: Computer Vision and Shape Recognition edited by A Krzyzak, T Kasvand \& C Y Suen

Forthcoming titles:

Volume 5: Information Control Problems in Manufacturing Automation by $L$ Nemes

Volume 7: Syntactic and Structural Pattern RecognitionTheory and Applications edited by $\mathrm{H}$ Bunke \& $\mathrm{A}$ Sanfeliu

Volume 11: Control of Robotic Systems by JM Skowronski

Volume 13: Mathematical Logic for Computer Science by $Z W L u$

Voume 15: Stochastic Complexity in Statistics and Information Theory by $J$ Rissanen 
Series in Computer Science - Vol. 14

\section{COMPUTER VISION and SHAPE RECOGNITION}

Editors

Adam Krzyzak

Tony Kasvand

Ching Y. Suen

Department of Computer Science

Concordia University

Montreal, Canada 
Published by

World Scientific Publishing Co. Pte. Ltd.

P O Box 128, Farrer Road, Singapore 9128

USA office: World Scientific Publishing Co., Inc.

687 Hartwell Street, Teaneck, NJ 07666, USA

UK office: World Scientific Publishing Co. Pte. Ltd.

73 Lynton Mead, Totteridge, London N20 8DH, England

\section{COMPUTER VISION AND SHAPE RECOGNITION}

Copyright $\odot 1989$ by World Scientific Publishing Co. Pte. Ltd.

All rights reserved. This book, or parts thereof, may not be reproduced in any form or by any means, electronic or mechanical, including photocopying, recording or any information storage and retrieval system now known or to be invented, without written permission from the Publisher.

ISBN 9971-50-862-1

Printed in Singapore by General Printing Services Pte. Ltd. 


\section{FOREWORD}

This book is composed of selected and expanded papers presented at the Vision Interface '88 Conference in Edmonton, Alberta, Canada, June 6-10, 1988. Focussed on computer vision and shape recognition, this book contains six parts:

1. Robot vision

2. Biomedical imaging

3. Remote sensing and parallel processing

4. Shape recognition and features

5. Computational methods in vision

6. Three dimensional vision and applications

Traditionally Canadian researchers in pattern recognition, image processing and related topics present their papers in IAPR or US sponsored conferences. Only once has the IAPR Conference been held in Canada (Montreal 1984) giving the Canadians a chance to present their research efforts on home turf.

Two years ago an attempt was made to organize regularly scheduled computer vision conferences with contributions from Canadian and American scientists. The first was held in Vancouver in June 1986 and the second in Edmonton 1988. This book contains our latest results presented at the second conference. By necessity the content is somewhat broad, the topics range from biomedical image processing to hardware designs. However, the major emphasis is on robot vision based on $3 \mathrm{D}$ range scanners and shape recognition in its many forms.

This book was typeset in the Department of Computer Science at Concordia University with the help of our secretary Ms. Halina Monkiewicz. We wish to express our sincere gratitude to her for her efficiency, patience and care throughout the preparation of this book. Thanks are due to all contributors and staff of World Scientific Publishing Co. for their collaboration to bring this book out at the earliest opportunity.

A. Krzyzak, T. Kasvand and C. Y. Suen

Montreal, September 1988 
This page is intentionally left blank 


\section{CONTENTS}

FOREWORD

I. ROBOT VISION

Measuring the Alignment Accuracy of Surface Mount

Assembly Circuit Board Masks

D. Gauthier, M. D. Levine, A. S. Malowany, N. Begnoche and $G$. Lefebvre

Model-Based 3D Object Localization \& Recognization from

21

a Single Intensity Image

Jason $W u$ and $T$. Caelli

Use of a Wrist Mounted Laser Range Finder

Colin Archibald

Segmentation of Range Images by Piecewise

Approximation with Shape Constraints

Jean-Marie Beaulieu and Pierre Boulanger

II. BIOMEDICAL IMAGING

The Extraction of Spatial Patterns from the Electroencephalogram .... 101

Z. J. Koles, A. Kasmia and M. S. Lazar

Automated Detection of Breast Tumors

S. Mei Lai, Xiaobo Li and Walter F. Bischof

III. REMOTE SENSING AND PARALLEL PROCESSING

Symbolic Knowledge Representation for Remote Sensing 135

Gordon W. Plunkett and David G. Goodenough 
Systolic Architectures for Structural Feature Extraction

Using Curve Tracing and Hough Transform

H. F. Li, R. Jayakumar, Derek Pao and M. Youssef

Parallel Computation of a Class of Non-Linear Hybrid

Filters and Their Implementation

Amelia Fong

IV. SHAPE RECOGNITION AND FEATURES

On-Line Gesture Recognition by Feature Analysis

Joonki Kim

Contour Tracing and Parametric Approximations for

\section{Digitized Patterns}

R. Legault and C. Y. Suen

Classification of Digitized Curves Represented by

Signatures and Fourier Descriptors
A. Krzyzak and
H. El Buaeshi

Thinning of Digitized Characters From Subjective

Experiments: A Proposal for a Systematic Evaluation

Protocol of Algorithms

Réjean Plamondon and Ching Y. Suen

V. COMPUTATIONAL METHODS IN VISION

Removing Specularities from Color Images

for Shape from Shading

Frank Tong and Brian V. Funt

The Composition and Control of Visual Routines

Marc H. J. Romanycia 
Estimating Movement Direction with a Neural Network

William C. Treurniet

A Graphics Package for Simulating the Data

of Range Finders

Stephen H. Y. Hung

\section{THREE DIMENSIONAL VISION AND APPLICATIONS}

Space Station - An Application for Computer Vision

Karl H. Doetsch and Richard C. Hughes

Experimental Results for Matching 3-D Range Data

Objects Based on a Statistical Approach

Nabih N. Abdelmalek

An Application of Syntactic Pattern Recognition 397

to Seismic Interpretation

Lawrence H. T. Le and Edo Nyland

Label Relaxation Technique Applied to the Stable

Estimation of a Topographic Primal Sketch

Pierre Boulanger

Integrating Methodologies in Image Analysis 429

Theo Pavlidis and Yuh-Tay Liow

The Image Processing Marketplace

R. C. Gonzalez

LIST OF CONTRIBUTORS 